\title{
MEMORIA SOBRE EL ESTADO DE LAS QUINAS EN GENERAL, Y EN PARTICULAR SOBRE LAS DE LOJA
}

FRANCISCO JOSE DE CALDAS

Primer Director del Observatorio Astronómico Nacional

y segundo de Mutis en la Expedición Botánica.
Los árboles de las diferentes especies de Quinas que nacen en los Andes Equinocciales, pueden ser tan ventajosos para España como to han sido para Holanda los de la Canela de Ceilán. Si hasta hoy no hemos cogido frutos tan abundantes, si el producto de la Quina no iguala ni con mucho al de la Canela, pende, sin contradicción, del abandono en que mantenemos este ramo, y tal vez de no haber reflexionado sobre las ventajosas circunstancias en que la Providencia le ha colocado. Estoy persuadido que una Memoria, en que se manifestase el estado presente de los bosques en que nacen estas plantas, su extensión, sus límites, corte, acopio, plantíos, etc. de algunas especies, y principalmente de la de Loja, sería muy interesante a la Nación. Este conocimiento, los deseos de contribuír al servicio del Rey y utilidad de sus vasallos, el amor que tengo a mi país, y la obligación de corresponder a las miras benéficas del Jefe (1), que hoy manda esta provincia, me han obligado a ordenar y reunir en ésta los conocimientos que he adquirido sobre la Quina en mis viajes dentro del Virreinato (2), y principalmente en el que acabo de verificar a la ciudad de Loja (3). iDi-

(1) El Barón de Carondelet, este celoso e infatigable Magistrado, que desde el momento que tomó el mando de la Provincia de Quito, no cesa de promover todos los objetos útiles al Rey, a la Nación y particularmente a esta porción de la Monarquía, me pasó el 9 de Enero de este año (1805) un oficio en que me ordena le manifieste los conocimientos que he traído de Loja sobre el importante ramo de las Quinas.

(2) En Julio de 1803, recorrí los bosques de Malbucho en solicitud de las Quinas. En Octubre del mismo año entré a Intag, pueblo situado en las faldas occidentales de la cordillera por $0^{\circ} 26^{\prime}$ de lat. boreal. En Julio de 1804, me interné en Tagualó, Macuchi, etc., como también en las faldas occidentales de la cordillera por $0^{\circ} 53^{\prime} 19$ " y $0^{\circ} 56^{\prime} 21^{\prime \prime}$ de lat. Sur, según mis observaciones. En Agosto-del mismo año recorrí los montes de Alausí, Sibambe por $2^{\circ} 10^{\prime}$ de lat. aus tral. En Septiembre los de Paute, Taday, Gualaceo, en las cercanías de Cuenca; y en fin pasé a visitar los de Loja en Octubre y Noviembre.

(3) La altura de Loja sobre el mar, su temperatura, producciones, etc., tienen mucha relación con lo que sigue, $\mathrm{y}$ he creído necesario dar una idea sucinta de esta ciudad.

Loja es un grupo de casas mal formadas en la mitad de un valle angosto y desigual, pero que se extiende de Norte a. Sur tres o cuatro leguas. Al Este tiene el ramo más Oriental de las Andes con el nombre de cordillera de Zamora, y por Oeste el cordón de Villonaco, que se reúne al principal en Cajanuma. El horizonte estrecho, los campos sin cultivo, unas casas medio arruinadas, las calles angostas y sucias, dan a Loja un aspecto tan melancólico que inspira deseos de salir de ella, cuanto antes. Colocada en medio de dos arroyos que se unen en la extremidad boreal de la población, goza de aguas puras y abundantes. En otros tiempos floreciente, se halla hoy en un estado bien miserable. Sus moradores no pasan de dos mil. Se pueden dividir en dos clases, por lo que mira a su ocupación. Los unos cultivan sus haciendas, que les producen maíz, azúcar, mulas excelentes y ganado vacuno; los otros viven en una perfecta ociosidad, y les conviene muy bien la fama de mexquinos que tienen en toda la provincia. Es de admirar la choso yo si estos trabajos llegan algún día a mejorar la suerte de uno solo!

La especie de Quina conocida por los botánicos con el nombre Cinchona officinalis, esa especie eminentemente febrífuga, bosquejada sobre esqueletos por el ilustre Mutis, y publicada por el caballero Carlos Linneo, no se halla esparcida como las otras

buena fe y paz en que viven unos hombres que no conocen el trabajo ni la generosidad. E1 robo es casi desconocido entre estos moradores. E1 terreno es de los más fértiles del Reino. Sin esfuerzos tienen con mediana abundancia los frutos de los temperamentos medios y de los ardientes. Estos los sacan del Catamayo, valle profundo al Occidente de Villonaco, y a seis leguas de Loja. La chirimoya, la más deliciosa de las frutas, crece espontáneamente. He atravesado bosques compuestos de estos árboles en la estación en que florecen. El aire se hallaba entonces perfumado con las exhalaciones de sus flores que se esparcía por todos los lugares. ¿Qué abundancia de plantas, de gomas, de cortezas, todas útiles á las artes y a la medicina! En el recinto de la ciudad no hay terciana; pero sus habitantes las toman en el Catamayo, de donde sacan la mejor parte de su subsistencia. Parece que en ninguna parte de nuestro globo, debía temerse menos esta enfermedad. No obstante, a pesar de hallarse rodeados de árboles de la mejor Quina, mueren sin recurso cuantos tienen la desgracia de ser atacados de ella, principalmente los indios en quienes hace los mayores estragos. Creen que esta corteza enciende la sangre y los humores, la miran con horror y la detestan. Es bien sabido en Loja, que para salvar la vida de estos infelices es necesario aprisionarle, y muchas veces usar de los castigos más severos para que tome el mejor y más poderoso remedio que se le puede administrar. La experiencia de todos los días nos enseña que el indio, religioso observador de lo que hicieron sus mayores, perpetúa sus usos, sus preocupaciones, sus secretos, sus vicios, y aun esa funesta inclinación a la idolatría. ¿Por qué no conserva también el uso de la Quina, si es cierto, como dicen de La-Condamine, Sabary, Ruiz, etc., que los españoles hallaron establecido entre ellos este remedio, y de quiénes le tomaron al tiempo o después del descubrimiento de la proquiénes le tomaron al tiempo o después del descubrimiento de la pro-
vincia de Loja? Llueve desde Octubre hasta Mayo, con la irregularidad que observamos en los lugares elevados de los Andes equinocciales: graniza poco, y el rayo no es tan frecuente como en Quito y Popayán. Desde Junio hasta Septiembre cesan las lluvias y reina un viento impetuoso del Este, acompañado de una llovizna menudísima sobre la cima de las montañas, a que dan el nombre de temporales o de páramos. Algunas veces son tan abundantes que llegan hasta la misma ciudad, y hacen casi impracticables los pésimos caminos de sus cercanías. Esta estación es la peor del año para atravesar de Quito a Loja. Tiene en sus inmediaciones minas de mármol blanco, semejante al de Cuenca, de yeso, de estaño en espato blanco, que, según Magraff, es el más puro, de asfalto, o betún de Judea, de antimonio, de cobre, muy abundantes de plata, de oro y de cristal de roca. Su temperatura es de las más agradables; el termómetro de $\mathrm{Mr}$. de Reaumur varía de $10^{\circ}$ a $16^{\circ}$, manteniéndose la mayor parte del año entre $14^{\circ}$ y $15^{\circ}$. La altura del mercurio en el barómetro es de 263,5 lin., medio entre un número prodigioso de observaciones. Mr. de La-Condamine halló primero 260,0 lín. (Mem. de la Acad. de las Cienc. de 1738) y después 266,0. (Mem. de la Acad. de 1745). La altura de esta ciudad sobre el Océano Pacifico es:

Toesas Varas Cast.

Según Mr. de La-Condamine............... 1.100,0 $=2.566$,
Según el Sr. Barón de Humboldt........ $1.006,0=2.347$, Según mis observaciones y cálculos........ 1.002,7 $=2.339,6$

Su latitud deducida de dos alturas meridianas del Sol, con un buen cuarto de círculo de I. Bird es de $4^{\circ} 01$ ' 02",5 Sur. Mr. de La-Condamine le da 40 01' 00 "' (Mem. de la Acad. 1738), resultado demasiado conforme a mis observaciones astronómicas. Su longitud es de $0^{\circ}$ 57 ' 30" al Occidente de Quito. 
de su género. Una porción del Corregimiento de Loja es la depositaria única de esta planta preciosa. Esta verdad, de que me creo ser autor, merece examinarse con alguna detención. Ella interesa al comercio, da luces para organizar su corte, acopio y libertad, y lo que es más importante, pone al Gobierno en estado de juzgar con firmeza sobre la economía de un ramo, que puede hacer felices a muchos miles de vasallos.

Para manifestar sus límites de un modo sensible, presentar los principios sobre que se deben apoyar nuestros discursos, las consecuencias y resoluciones ulteriores sobre la Quina, he formado una pequeña Carta topográfica de las inmediaciones de Loja, y un perfil, o corte de la cordillera de los Andes en la latitud más conveniente. Los fundamentos de aquella son muchas observaciones astronómicas, medidas, etc., verificadas sobre los mismos lugares, juntas a los trabajos de los ilustres La-Condamine y Maldonado. Abraza $1^{\circ} 47^{\prime}$ en latitud, y $2^{\circ} 30^{\prime}$ en longitud, contando ésta del meridiano de Quito. Esta que llamaré Nivelación barométrica está apoyada sobre un gran número de observaciones de este género, hechas con el mayor cuidado, y sobre mis cálculos muchas veces repetidos, usando en ellos de las mejores fórmulas que tenemos. Es necesario notar en esta nivelación, lo siguiente:

A la derecha se hallan cuatro escalas: la $1^{a}$ expresa la altura de la columna de mercurio en pulgadas y líneas; la $2^{\text {a }}$ en líneas solamente; la $3^{\text {a }}$ las toesas que hay de una pulgada a otra del barómetro; y la $4^{\text {a }}$ Ia suma de toesas contadas desde la superficie del mar. La línea más baja representa el nivel del Océano Pacífico; sus paralelas hacia arriba las Zonas o capas diferentes de la atmósfera, que equivalen a la presión de una pulgada de mercurio, y que aumentan su anchura en razón de las densidades del aire a proporción que se sube.

La Quina de Loja no se halla sino desde los $3^{\circ} 44^{\prime}$ de lat. aust., faltando del todo en otra latitud menor que la asignada. Puedo lisonjearme de conocer, si no todas las especies propias de la Provincia de Quito, a lo menos la mayor parte. Las he visto vivas y cuidadosamente diseñado y descrito: poseo esqueletos y cortezas con que voy a enriquecer la Flora de Bogotá, y ninguna se parece a las que producen las cercanías de Loja. Este límite puesto por las manos de la naturaleza y que llamo término boreal de la Cinchona officinalis, comienza en el ramo que divide las aguas entre el río de Saraguro y el de Loja, que toma después el de Zamora, y entra en el Marañón, bajo del de Santiago. Véase la Carta adjunta.

Desde Ayabaca desde $\operatorname{los} 4^{\circ} 40^{\prime}$ de latitud austral hacia el Sur, ya no re vuelve a encontrar esta especie. Se citará la autoridad de Ruiz (1) para ensanchar este límite. Pero a pesar del respeto que debo a los conocimientos de este botánico, debo decir, que si se compara la descripción que nos ha dado de ella con la que he visto en Loja, si nos acordamos que el autor de la Quinología del Perú, jamás estuvo en los

(1) Quinología, pág. 57. bosques de las inmediaciones de esta ciudad, se convendrá en que la Cinchona officinalis de este laborioso profesor difiere mucho de la Quina roja de que hablamos. Estaría aquí fuéra de su lugar un pormenor circunstanciado sobre este objeto. Pero reflexionando que hablo en una materia delicada, y que tiene consecuencias, reservo su resolución para cuando restituído al lado del mayor botánico de que puede gloriarse la Nación, oiga su juicio y pueda consultar mejores libros. Por ahora baste saber que de Ayabaca hacia el Sur falta esta especie por el espacio de muchas leguas, que en toda la extensión de la Provincia de Quito sólo Loja produce la Cinchona officinalis de Linneo, y que aun aquí está confinada dentro de $3^{\circ} 42^{\prime}$, y $4^{\circ} 40^{\prime}$ de latitud austral. Llamo a este último límite término austral de esta especie de Quina.

No hay que apoyarse sobre la analogía perfecta de la temperatura, elevación y vecindad de los países para creer que esta especie se halla también en ellos. ¿Qué lugares más semejantes, por no decir iguales a los de Loja, que Saraguro, Cuenca, Sibambe, Paute y otros? Pues a pesar de hallarse estos casi en la misma temperatura, la misma presión atmosférica, y casi la misma latitud, no se halla en ellos un árbol de la Quina que producen las cercanías de Loja.

No se crea que esta bella Cinchona nace en todas las elevaciones posibles de los Andes. Huye tanto de los climas helados como de los ardientes, y sólo prospera en la región media (1) de la cordillera. Una presión atmosférica que exceda el peso de una columna de mercurio de 23 pulgadas, o que sea menor de 20 , y una temperatura que no esté dentro de $4^{\circ}$ y $18^{\circ} \mathrm{R}$. son poco favorables, o más bien adversas a la vegetación de esta planta. Muchas observaciones en diferentes lugares de los bosques en que nace, me han enseñado que estos son los límites en que se halla confinada. Por consiguiente el término inferior está a $813, \check{a}$ toesas (1.898,2 varas cast.) sobre el mar, y el término superior a $1.380,0$ toesas $(3.220,0$ varas cas.) ; la zona en que prospera tiene solamente 566,5 toesas (1.321,8 varas cast.) de anchura, y su centro $1.096,7$ toesas (2.558,9 varas cast.) elevado sobre el mar.

Esta propiedad de la Quina de Loja, unida a la disposición del terreno que la produce, le ponen límites de Oriente a Poniente. Para formar una idea clara de este punto interesante, es preciso acordarnos que las montañas depositarias de esta Quina, hacen parte de los Andes, que, como todos saben, co-

(1) Hablando con rigor, el centro de la zona en que vegeta la quina se halla a $1 / 3$ de toda la altura de los Andes. Con este objeto he puesto sobre el perfil una vista del Chimborazo tomada de la nueva Riobamba. Esta cima, la más elevada de la tierra, tiene, según las recientes observaciones del Barón de Humboldt, 3.267 toesas sobre el mar. Ahora: $\frac{3.267}{3}=1.089=\frac{1}{3}$ de los Andes.

El término superior de la vegetación de la Quina está 1.380,0 toesas sobre el mar: el inferior 813,5 toesas: luego $1.380,0-813,5=566,5$ : $\frac{5.666,5}{2}=283,2+813,5=1,096,7$ altura del centro de la zona de la vegetación de la Quina.

Altura del centro de la zona........... 1.096,7

Un tercio de los Andes.... . . . . . . . . 1.089,0

Diferencia......... 7,7 toesas 
rren constantemente de Norte a Sur, del un hemisferio al otro, siempre inmediatos y paralelos a las costas occidentales del nuevo continente. Si contamos de Poniente a Oriente esta famosa cordillera en latitud de Vilcabamba (1), que ocupa el centro del domicilio de la Quina (2), si le representamos en perfil con todo lo restante de la América Meridional desde Tumbes sobre el Pacífico, hasta el Pará en las costas del Atlántico, tendremos una sección semejante a la que presenta la Nivelación que acompaño. Echemos una ojeada rápida sobre ella, y hallaremos :

Que lo primero que se presenta a la derecha son las aguas del Océano Pacífico, y (*) el puerto de Tumbes, comienza a elevarse el terreno poco a poco. Primero se hallan colinas pequeñas que van aumentando su altura a proporción que se alejan de la costa, pero que no alcanzan sus cimas a tocar el término inferior de la Cinchona, es decir, que no tienen 813,5 toesas $(1.898,2$ v. c.) de altura perpendicular sobre el Océano. Por 615,6 toesas (1.436,4 v. c.) está Zaruma. Desde aquí se levantan montañas sobre las colinas, que pasando el término inferior A de la Cinchona, van casi a tocar el término superior por $1.380,0$ toesas $(3.220,0$ v. c.) de elevación. Este es el famoso Uritu-singa (3). Aquí comienza a descender el terreno hasta la ciudad de Loja, que, como hemos dicho, se halla a $1.002,7$ ts. $(2.339,6$ v. c. $)$ de elevación. Vuelve a subir en Cajanuma (4), baja hasta Malacatos, Cararango y Vilcabamba. Después de este último punto se eleva sin interrupción hasta las 14-1500 toesas, y forma la Cordillera de Zamora, que es el ramo más oriental de los Andes, y el que divide las aguas entre el Marañón y Catamayo, o Colán. Al Este no se presenta otra cosa que un descenso continuado hasta Zamora y Tomependa (5) sobre el Amazonas. En Tomependa comienza la inmensa llanura que va a terminar en las costas del Brasil, en cuya extremidad se ven el Pará y las aguas del Océano Atlántico.

Al primer aspecto de esta Nivelación se manifiesta que en todo el inmenso espacio de la América Meridional, que en las 900 leguas que tiene de Este a Oeste en el paralelo de $4^{\circ} 5^{\prime}$ de lat. aust., sólo la cor-

(1) Por tres alturas meridianas del Sol, hallé que este pueblo está a $4^{\circ} 18^{\prime} 30^{\prime}$ " de lat. austral.

(2) Véase la Carta topográfica adjunta.

(*) Talvez, debe ser desde el. (Nota del Editor).

(3) Uritu-singa. Montaña situada al Occidente de Loja, y que se extiende desde Malacatos hasta el Gisne y Santiago por el espacio de 8-9 leguas náuticas. Al frente, y justamente al Oeste de la ciudad de Loja forma una cresta de roca erizada, $y$ en lo más alto de ella una punta que tiene semejanza con el pico de un papagayo, de donde le viene el nombre de Uritu-singa. Esta palabra es compuesta de dos de la lengua del Perú. Uritu, que significa papagayo, y singa, nariz, o pico. Es fértil en Quinquina, y la que há más de un siglo da grandes cantidades de esta corteza sin agotarse.

(4) Cajanuma. Más bien es una falda pequeña que Uritu-singa suelta para reunirse a la cordillera de Zamora, que una montaña separada; ella forma la división de aguas entre el río de Zamora y el Catamayo. Aquéllas van al Mar Atlántico, y éstas al Océano Pacífico. E1 barómetro se sostiene sobre Cajanuma en 252,5 líneas, lo que enseña que la cima de este cordón está a $1.172,7$ toesas sobre el mar $(2.736,0$ v, c.) y 170,0 toesas $(396,6$ v. c.) sobre Loja. Abunda como en Uritusinga, la más bella Quina.

(5) He colocado a Tomependa en 168,0 toesas $(392,0$ v. c.) de altura según las observaciones del Barón de Humboldt. dillera de Zamora en los puntos B y C, y las montañas de Uritu-singa, y de Zaruma en A y D tocan el término inferior de la Cinchona officinalis. Es, pues, evidente que esta planta no puede hallarse, sino desde A hasta B. Este es el término oriental, y aquél el occidental de la Quina de Loja. El primero está por $1^{\circ} 45$ ', y el segundo por $0^{\circ} 35$ ' al Occidente del meridiano de Quito.

De todo lo dicho resulta que tenemos seis Términos, dentro de quienes se halla confinada la Quina, términos cuyas diferencias nos dan la extensión de las tres zonas diferentes de que acabamos de hablar, y términos, en fin, que nos enseñan el punto de vista bajo del cual debemos considerar el plantío, comercio, cultivo, acopio, etc. de la Quina. En resumen son:

Término austral........... $4^{\circ} 40^{\prime}$ de lat. aust. Término boreal........... $4^{\mathrm{O}} 42^{\prime}$ de lat. aust. Diferencia.......... $\overline{0^{\circ} 58}$

Término oriental.......... $\overline{0^{\circ} 35}$, Octe. Quito Término occidental.......... $1^{\circ} 45$ ' Octe. Quito Diferencia........... $\overline{1^{\circ} 10}$,

Término inferior....... 813,5 toes. sobre el mar Término superior...... $1.380,0$ toes. sobre el mar Diferencia....... $\overline{566,5}$ Semidiferencia.... 283,2 $+813,5$

Alt. del centro de la zona $\overline{1.096,7}$

A éstos podemos añadir las temperaturas de los dos últimos términos; serán:

Temperatura del término superior mín. $4^{\circ}, 0 \mathrm{R}$ Temperatura del término inferior máx. $18^{\circ}, 0$

Diferencia................ $\overline{12^{\circ}, 0}$

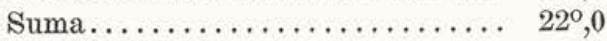

Temperatura media............. $11^{\circ}, 0$

Con estos conocimientos podemos ya apreciar por una juiciosa aproximación el número de leguas que producen la Quina más estimada. En la Carta Topográfica que acompaño, he bañado de color pajizo el terreno que es fértil en ella, para que a primera vista se distinga de las demás. El está encerrado comenzando por el Norte entre el río de las Juntas, que toma su origen en las montañas de Saraguro hasta la embocadura del pequeño río de Santiago. Este hacia arriba hasta su nacimiento en la montaña del Cisne. Después del río de este nombre hasta su embocadura en el Catamayo. En fin, siguiendo este río hasta su unión con el de Macará, que le entra por $\operatorname{los} 4^{\circ} 20^{\prime}$ de lat. aust. y por $1^{\circ} 50^{\prime}$ al Occidente de Quito. Por el Sur está confinado dentro del río de Macará, montañas de Ayabaca, Valladolid, hasta su unión en la cordillera de Zamora que le termina por el Oriente.

El espacio que encierran estos límites se ve dividido en muchos cuadrados formados por líneas de puntos que se cortan en ángulos rectos distantes entre sí una legua nántica de 20 al grado, o de 2.837,5 toesas $(6.620,8$ v. c.) Basta, pues, contar estas cua- 
Rev. Acad. Colomb. Cienc. Ex. Fis. Nat. 42(Suplemento):30-39, octubre de 2018 doi: http://dx.doi.org/10.18257/raccefyn.734

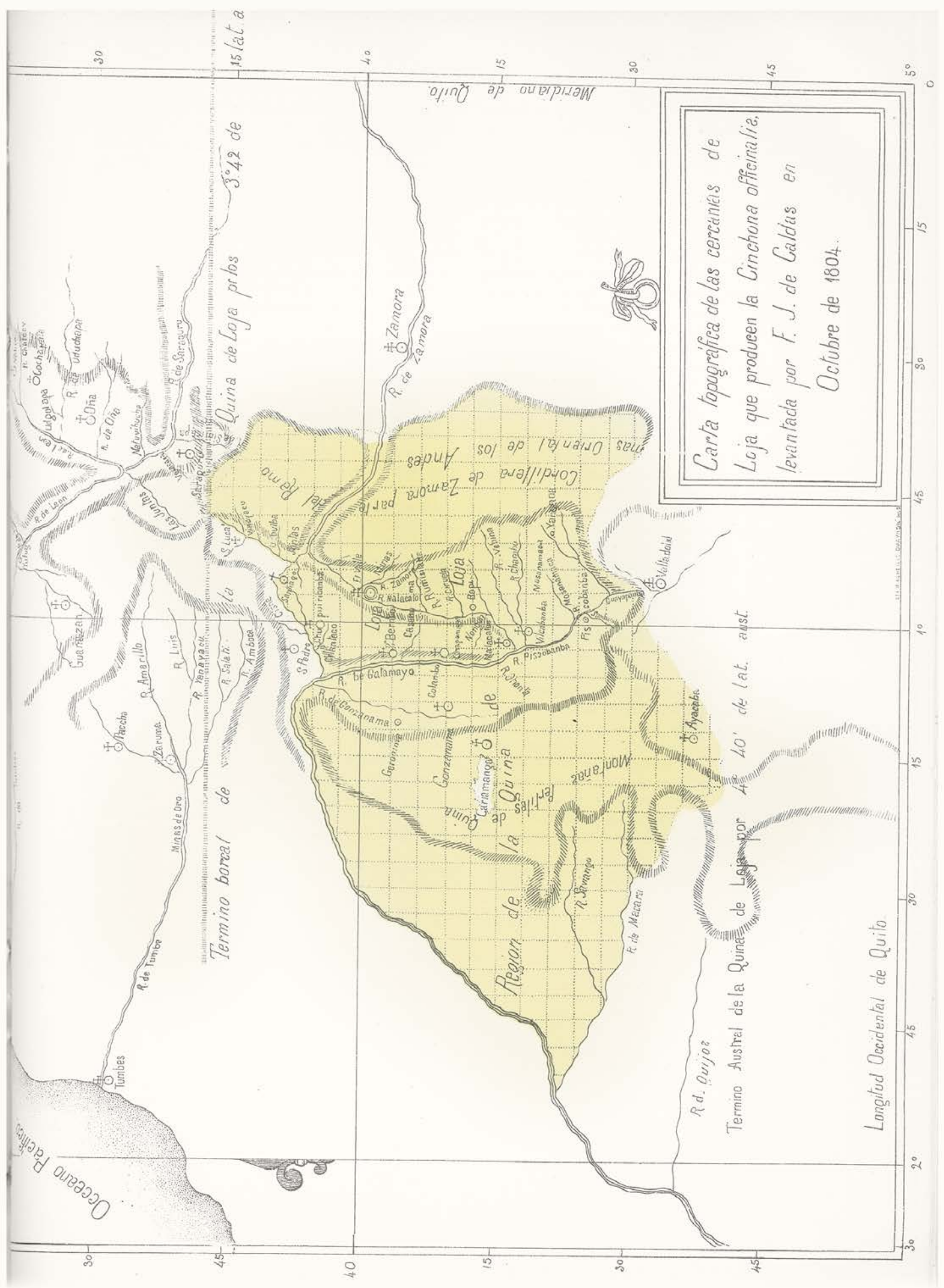


drículas para saber el número de leguas cuadradas que hay en el recinto que acabamos de señalar. He hallado que son 275. Quitemos 100 leguas por los pequeños valles que más bajos que el término inferior de la Nivelución, no producen ningún árbol de Quina. Quedarán 175 leguas cuadradas útiles. Bien podemos añadir sin temor de exageración 25 leguas por el aumento de superficie causada por las montañas que se enlazan y cruzan en direcciones diferentes por todas partes, no habiendo más espacio de una a otra que el lecho de los arroyos que las separan. Tenemos, pues, 200 leguas cuadradas fértiles en Quina, leguas que han dado un número incalculable de quintales desde que se extrae su corteza, y que parecen inagotables.

Es de admirar que en 167 años que há conocemos las virtudes de la Quina, no hayamos pensado en transportarla a otros lugares análogos del Virreinato. ¿Quién creyera que este árbol, cuya corteza asegura la vida inestimable de nuestros Soberanos, de la familia Real de España, y la de sus vasallos, había de permanecer hasta hoy confinado en el estrecho recinto que acabamos de prescribirle? Más afortunados el Algodón y el Cacao, han sido transportados a todos los lugares en que se ha creído prosperarían. ¿Habián influído en esta injusta preferencia las prontas ventajas que percibe el cultivador? ¿Serán las caprichosas vicisitudes a que han estado expuestas las cortezas de la Quina? Sea la que fuere la causa, lo cierto es que no tenemos un solo árbol de Quina de Loja en toda la extensión del Virreinato.

¡Cuántos lugares absolutamente análogos al de Loja tenemos en las provincias de Quito y Santa Fe! ¿Cuántos centenares de leguas con la misma temperatura, la misma elevación, la misma presión atmos. férica y las mismas estaciones! La Quina transportada a estos países prosperaría seguramente con la mayor felicidad. Todos los bosques, todos los lugares cuya latitud no pase de $12^{\circ}$, en quienes el barómetro se sostenga de 241 a 277 límeas (de $20-23$ pul- gadas) es decir, que su elevación sobre el mar sea de 813,5 a $1.380,0$ toesas (de $1.898,2$ a $3.220,0$ v. c.) son propios para el plantío de este vegetal, cuyo incremento feliz lo debemos esperar con la mayor seguridad. Si es cierto que en la vecindad de la línea la altura decide del calor, si es cierto que a igual elevación, la carga eléctrica, la cantidad de oxígeno y la presión atmosférica son las mismas, ¿qué debemos temer en el trasplante y cultivo de esta especie preciosa? Guaillabamba (1), Otavalo, todas las cercanías de Ibarra, Quito y alrededores, Intag, valles de Chillo y de Tumbaco, Jalupana, Pilaló, Minas de Macuchi, Ambato, Riobamba, Alausí, Sibambe, Cuenca, Azogues, Paute, Gualaceo, infinitos lugares de la provincia de Popayán; otros tantos de las inmediaciones de Santa Fe, Socorro, etc., etc., son propios para establecer inmensos plantíos de esta Quina. Pero entre todos los que conozco, ninguno más aparente, ninguno más análogo al de Loja, que el suelo de Popayán. Su temperatura (de $10^{\circ}-17^{\circ}$ R.) ; su presión atmosférica ( 275,2 líns. del barómetro); su altura sobre el mar (901 toesas, 2.102 v. c.); la cualidad de su terreno, las plantas que produce espontáneamente son del todo iguales a aquella en que prospera tan bien la mejor Quina de Loja. Cré hacer un presente interesante a mi patria, transportando a ella diez plantas jóvenes. Pero la estupidez o malignidad del indio que las conducía a espaldas me privó de esta satisfacción, y a Popayán de un fondo considerable de bienes y de riqueza. Ah!, si algunos de los hombres pudientes de aquella ciudad, si alguno de los de Quito, Riobamba, Cuenca, Santa Fe, emprendiesen transportar algunas plantas de esta Quina a sus respectivos lugares, si la cultivasen con cuidado, si la propagasen hasta el punto de poder hacer colecciones abundantes de su corteza, ¡qué comercio, qué felicidad para unos pueblos, depositarios únicos del más poderoso específico de que puede gloriarse la medicina para restablecer la saInd del hombre en las cuatro partes del mundo! Esta corteza nos presentaría relaciones, y nos uniría

(1) Ponemos aqui una tabla de muchos lugares del Virreinato, cuya altura barométrica está dentro de 241 y 277,0 , su elevación sobre el mar entre ( 1.898 y 3.220 varas castellanas) como propios para el cultivo de la Quina de Loja. El * denota que la altura se ha tomado

\begin{tabular}{|c|c|c|}
\hline UGARES & $\begin{array}{c}\text { Altura } \\
\text { barométrica. }\end{array}$ & $\begin{array}{l}\text { Altura sobre el } \\
\text { mar en baras } \\
\text { castellanas. }\end{array}$ \\
\hline aillabamba & 263,6 & $2.335,9$ \\
\hline 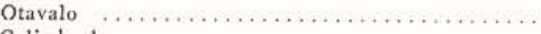 & & \\
\hline 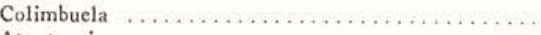 & & \\
\hline 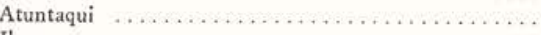 & & \\
\hline & & \\
\hline 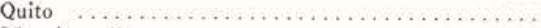 & & \\
\hline llanura...$\ldots \ldots \ldots \ldots \ldots \ldots \ldots \ldots$ & & \\
\hline 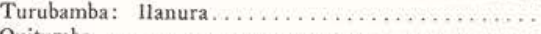 & & \\
\hline 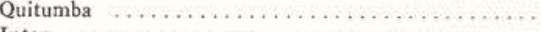 & & \\
\hline$\cdots \ldots \ldots \ldots$ & & \\
\hline 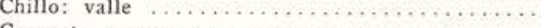 & & \\
\hline 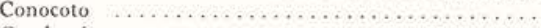 & & \\
\hline$\ldots \ldots \ldots \ldots \ldots \ldots \ldots \ldots \ldots \ldots$ & & \\
\hline & & \\
\hline 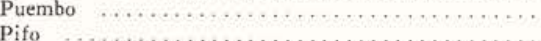 & & \\
\hline 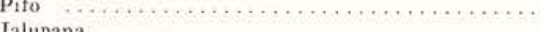 & & \\
\hline & & \\
\hline : $\mathrm{mi}$ & & \\
\hline & & \\
\hline & 249,5 & 3.075 , \\
\hline
\end{tabular}

(b) En el original no hay asteriscos, sin duda por olvido del copista. (N. del E.)

\begin{tabular}{|c|c|c|}
\hline LUGARES & $\begin{array}{c}\text { Altura } \\
\text { birrométrica. }\end{array}$ & $\begin{array}{l}\text { Mltura sobre el } \\
\text { mar en raras } \\
\text { castellauas. }\end{array}$ \\
\hline Riobamba $\ldots \ldots$. & 245,0 & $3.304,0$ \\
\hline 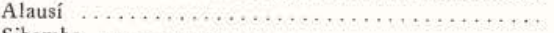 & 256,0 & $2.614,7$ \\
\hline 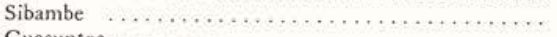 & 253,5 & $2.708,3$ \\
\hline Guasuntos $\ldots \ldots \ldots \ldots \ldots \ldots \ldots \ldots \ldots \ldots \ldots \ldots \ldots \ldots \ldots \ldots \ldots$ & 251,8 & $2.727,4$ \\
\hline 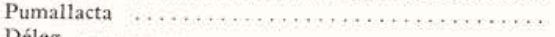 & 241,4 & $3.174,2$ \\
\hline 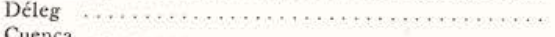 & 247,7 & $2.928,8$ \\
\hline Cuenca $\quad \ldots \ldots \ldots \ldots \ldots \ldots \ldots \ldots \ldots \ldots \ldots \ldots \ldots \ldots \ldots \ldots \ldots \ldots$ & 250,5 & $3.010,0$ \\
\hline Azogues $\quad \ldots \ldots \ldots \ldots \ldots \ldots \ldots \ldots \ldots \ldots \ldots \ldots \ldots \ldots \ldots$ & 250,6 & 2.8 \\
\hline Paute $\ldots \ldots \ldots \ldots \ldots \ldots \ldots \ldots \ldots \ldots \ldots \ldots \ldots \ldots \ldots \ldots \ldots \ldots$ & 261,9 & $2.397,7$ \\
\hline 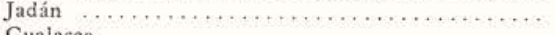 & 246,7 & $2.867,3$ \\
\hline Gualaceo $\quad \ldots \ldots \ldots \ldots \ldots \ldots \ldots \ldots \ldots \ldots \ldots \ldots \ldots \ldots \ldots$ & 260,1 & $2.463,3$ \\
\hline Tarqui $\quad \ldots \ldots \ldots \ldots \ldots \ldots \ldots \ldots \ldots \ldots \ldots \ldots \ldots \ldots \ldots \ldots \ldots \ldots$ & 245,6 & $3.178,0$ \\
\hline$\cdots \cdots \cdots \cdots \cdots \cdots \cdots \cdots \cdots \cdots \cdots \cdots$ & $\begin{array}{l}244,5 \\
2530\end{array}$ & $3.213,0$ \\
\hline 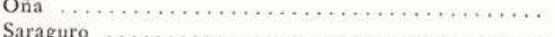 & 253,9 & $2.807,0$ \\
\hline $\begin{array}{l}\text { Saraguro } \ldots \ldots \ldots \ldots \ldots \ldots \ldots \ldots \ldots \\
\text { Pasto }\end{array}$ & 250,0 & $2.838,8$ \\
\hline $\begin{array}{l}\text { Pasto } \\
\text { Venta guemada }\end{array}$ & 249,8 & 2.84 \\
\hline $\begin{array}{l}\text { Venta quemada } . . . \ldots . . . \\
\text { Popayán }\end{array}$ & 275,5 & $1.915,4$ \\
\hline $\begin{array}{l}\text { Popayán } \ldots \ldots \ldots . \\
\text { Poblasón }\end{array}$ & 275,2 & $2.102,0$ \\
\hline $\begin{array}{l}\text { Poblasón } \quad \ldots \ldots \ldots \ldots \ldots \ldots \ldots \\
\text { Chiribio }\end{array}$ & 258,9 & $2.487,4$ \\
\hline 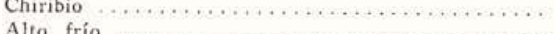 & 258,0 & $2.540,7$ \\
\hline $\begin{array}{l}\text { Alto frío } \ldots \ldots \ldots \ldots \ldots \ldots \ldots \ldots \ldots \ldots \ldots \ldots \ldots \ldots \ldots \ldots \ldots \ldots \ldots \ldots \ldots \\
\text { Santafc }\end{array}$ & 261,0 & 2.43 \\
\hline Santafé $\quad \ldots \ldots \ldots \ldots \ldots \ldots \ldots$ & 247,3 & $3.143,0$ \\
\hline
\end{tabular}


con las extremidades de la tierra. Más preciosa que el oro y que la plata merece preferirse a ese montón de proyectos quiméricos, siempre desgraciados, $\mathrm{y}$ de quienes no hemos sacado otro fruto en muestros climas, que familias arruinadas y menligos.

Los trasplantes a los Andes equinocciales, y no a Europa son los que se deben promover. No creo que una planta que ama una presión atmosférica de 23 pulgadas barométricas, cuando más, que perece en una temperatura de $2^{\circ} 0^{\prime}-4^{\circ} R$., que le es necesaria una llnvia abundante por el espacio de 9 meses, etc., pueda prosperar en Vizcaya, Galicia, Catalu. ña y Andalucía, como piensa Ruiz (1), a una piesión de 27 pulgadas, m calor de $28-30^{\circ} R$. en estio y un frío de $5^{\circ}-0^{\circ}$ en invierno, etc., etc.

De las 200 leguas cuadradas que producen esti Quina, sólo 16 o 20 de las cercanías de Malacatos, Vilcabamba y Gonzanamá están casi agotadas; las restantes se hallan intactas. Creo que con algunos reglamentos que extingan los abusos y corrijan la ignorancia de los cascarilleros (2) se puede asegurar para siempre no sólo la cantidad necesaria para subvenir a las necesidades de la Real Botica, sino también para establecer un comercio ventajoso.

El abuso más perjudicial que ejecutan los cascarilleros es cortar cuantos árboles encuentran en sus correrías, sin cuidar de la semilla para lo futuro. De aquí no hallarse sino con grandes dificultades una flor o una semilla en el espacio de muchas leguas, y extinguir en su origen la reproducción de la especie. Todos los árboles que hoy existen en el recinto de donde se acostumbra extraer la corteza son renuevos de dos, cuatro, o cuando más seis años. Por fortuna, en este corto espacio de tiempo se hallan en estado de volver a suministrar nueva corteza. Con este objeto les cortan de nuevo antes de florecer, y sin que llegue a su perfección la semilla que le debe perpetuar. Es, pues, de la última importancia conservar algunos individuos, imponiendo penas al cascarillero, que por malicia los corte, celando y visitando cada año los lugares en que estén los árboles reservados.

Muchos de los acopiadores descortezan el tronco, rompen los ramos del modo más rústico y grosero, se aprovechan de la corteza e inutilizan para siempre este individuo, pues maltratado de este modo se seca sin recurso. Otros, el primer paso que dau, es cortar el árbol por su base, práctica insensata, pero menos perjudicial que la anterior. El tronco principal, arroja dos, tres, y algunas veces cinco renuevos. A esta reproducción bienhechora de la naturaleza debemos los individuos que actualmente proveen al Rey, y a nuestras boticas. Sin ella habrían tal vez extinguido la especie. Son muy juiciosas las reflexiones de D. Hipólito Ruiz en su Quinología, Art. $3^{\circ}$, pág. 13 , que creo se deben adoptar en la extracción de la Quina de Loja.

Los dueños de haciendas hacen terribles perjuicios a los bosques de Quina. En los meses de Agos-

(1) Quinologîâ, pág. 21.

(2) Este es el nombre que se da en Loja y en el Perú a los peones que se ocupan en extraer y beneficiar la Quina. to $y$ de Septiembre ponen fuego a todas las faldas de las montañas para renovar los pastos. Muchas veces se apodera éste de los bosques inmediatos, y re duce a cenizas una, dos y muchas veces más leguas. En 1803 se incendió de este modo un espacio que, a juicio de un experimentado cascarillero, podía haber dado muchos quintales de la más bella y sa\%o. nadla Quina. Yo he sido testigo de otro incendio se mejante que duró dos noches y un día.

C'adla año se dificulta más la extracción y acopio de la Quina que se remite a España, de cuenta de S. M. El cascarillero tiene ya que internar muchas leguas para recoger dos o cuatro arrobas que se le han asignado por el Corregidor, y día llegará en que sea necesario duplicar y aun triplicar la cantidad que hoy paga el Rey por cada arroba. Este grave inconveniente se habría evitado, si los que están encargados de esta comisión hubieran atendido al corte, y no hubieran despreciado los plantíos tántas veces encargados por $\mathbf{S}$. M. Es de admirar que una planta de este interés se halle abandonada a sólo la fecundidad natural de los bosques de Loja, y es aún más admirable se haya dejado expuesta por tántos anos a la mano destructora del bárbaro cascarille. ro. No se puede ór sin dolor, que no existe hoy un solo árbol de plantío en todo el distrito del Corregimiento de Loja; y que en Octubre de 1804 estaban las cosas en el mismo estado que tenían al tiempo de su descubrimiento. Estoy persuadido que sólo los plantíos podrán detener la ruina, o a lo menos las dificultades inmensas, que se van presentando todos los días en el acopio de aquella cantidad que cada año se remite a la Botica Real. No hay que prestar. ó́dos a las dificultades que oponen los encargados y acopiadores para la consecución de los plantíos que proponemos. Todas ellas son hijas de su iguorancia o de su pereza. Me detendría en uombrarlas, pero cualquiera hombre sensato conocerá su futilidad al proponérselas. No obstante, hay una que des. lumbra a primera vista. Dicen que la Quina ama la sombra de los bosques y que perece cuando no se halla rodeada de árboles corpulentos. Un vecino homado y curioso de Loja quiso comprobar con la experiencia un hecho que arruinaba de un golpe el proyecto, y las más lisonjeras esperanzas que prometeu los plantíos. Transportó cuatro plantas jóvenes al patio de las casas capitulares de aquella ciudad en donde prosperaron felizmente. Aún existieran si en Loja se tomara algún interés en el asunto de las Quinas. Con la muerte de aquel hombre celoso se introdujeron caballos en el lugar en que estaban los cultro árboles de Quina, quienes los destrozaron e hicieron perecer.

Hay tánta oposición entre los liabitantes de Loja a los plantíos, que es necesario tomar las más serias providencias para que los ejecuten, y que el tiempo y la experiencia vayan arrancando una preocupación tan envejecida. Confieso que se necesita pulso para elegir el hombre a quien debe confiarse una comisión tan delicada. Si por desgracia recae sobre algún ignorante en materia de plantíos, aumenta- 
mos el mal que queremos precaver. Arrancará muchos cientos de plantas jóvenes de los bosques, los transportará a los lugares destinados a los plantíos, aquí perecerán por su ignorancia, y habrá despoblado al mismo tiempo las montañas.

Un árbol de Quina de $30-40$ años de edad, produce $3-4$ arrobas de corteza: otro de $5-6$ proveniente de renuevos sólo da de 12-14 libras. Por consiguiente, para recoger 500 arrobas son necesarios mil árboles, que no podrán volver a suministrar. corteza hasta los 5 o 6 años siguientes. Para lleuar. este vacío es preciso tener seis mil plantas en el mismo estado qu las primeras. En suma, si se quiere remitir todos los años 500 arrobas a S. M. y precaver todo inconveniente, es indispensable que los plantíos no bajen de diez mil plantas.

Los empleados, sueldos, etc. de los que se ocupau en el acopio y remisión de la Quima, son: el Corregidor de Loja tiene el mando y dirección con 500 pesos anuales. Hay un Profesor de Botánica y Química, con mil pesos cuando se mantenga en la ciudad, y dos mil si verifica alguna expedición. Un Factor con doscientos pesos para almacenar, encajonar, etc. Un Guarda mayor residente en Malacatos para verilicar la extracción de la corteza, con cien pesos. Cincuenta peones llamados cascarilleros, todos domiciliados en Malacatos, Vilcabamba y Gonzanamá. Por el mes de Junio el Corregidor asigna a cada uno de éstos la cantidad de arrobas que debe entregar en Diciembre, conforme su robustez, agilidad y práctica. Se le adelanta el valor a razón de veinte reales por arroba. El cascarillero se provee de carnes y demás bastimentos en Junio; en Agosto se interna en el bosque, de donde sale con la porción a su cargo; en Diciembre la lleva a Loja, en donde se encajona y remite a Piura en Enero a manos de aquellos Oficiales Reales que deben embarcarla para el Callao.

Un quintal de corteza puesta en Piura cuesta al Rey 33,4 pesos. Porque si sumamos los sueldos, valor de la Quina en Loja, cajones, forros, fletes, si dividimos esta suma por el número de arrobas, nos dará el valor de cada una de éstas, y por consiguiente del quintal.

Sueldos ..................... 1.800 pesos

Valor de 500 arrobas de Quina en Loja $1.250 "$

Cajones, forros, etc. ........... 625 "

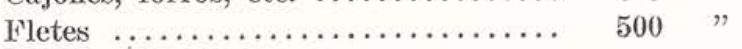

Suma............ 4.175 pesos

Alora: $4.175: 500=8,35 \times 4=33,4$ pesos

Cuántos abusos!, cuántas injusticias hay que coregir en este establecimiento! Dependiente sólo de la Corte a tres mil leguas de distancia, sin un Jefe que vele de cerca sobre el buen orden de este ramo, no es extraño se abuse de la sencillez del cascarillero, y se respeten poco las órdenes de S. M. Indicar aquí todos los vicios de esta Factoría, y de que yo mismo soy testigo, sería hacer demasiado larga esta Memoria. Pero no puedo callar sin hacer traición a mi Patria y al Soberano, la inacción en que ha 13 años se mantiene el Profesor de Botánica. Sí, este joven ha frustrado las más bellas esperanzas que concibió el Gobierno cuando lo destinó a Loja. Véanse las páginas 26 y 92 de la Quinología de Ruiz: allí están descritas las operaciones que debían haberle ocupado desde su arribo a la provincia de Loja. ¡Cuántos conocimientos utilísimos perdidos! ¡Cuántas luces interesantes a la salud del hombre malogradas! ;Cuántos perjuicios a la Botánica, a la Quí mica, al Comercio, y al honor de la Nación!

Mientras este profesor se mantenga, por decirlo así, en la independencia, mientras no pertenezca a un Cuerpo que le estimule, que vele sobre sus operaciones, que tome cuenta con frecuencia, no tenemos que esperar ningún progreso sobre el importante ramo de la Quina de Loja. Estando este Corregimiento dentro de los límites del Virreinato de Santa Fe, existiendo en esta Capital una Expedición Real Botánica, teniendo por Director a un Mutis, a este sabio que tánto ha profundizado sobre el género Cinchona, y de cuya infatigable actividad no pueden dudar, sino aquellas almas envidiosas de su gloria. ¿No es demasiado conforme a la razón y al buen ordeu sujetar en todo a sus luces al Botánico que se halla en la ciudad de Loja? Así reunido comenzaría el mundo sabio, la Nación, la humanidad, el Soberano a coger el fruto que ha 13 años espera de manos de Don Vicente Olmedo. Impaciente el célebre Mutis por comparar sus Quinas con la de Loja y demás que produce la Provincia de Quito, desesperando de conseguirlo por los escritos del Botánico de aquella ciudad, me destinó a colectarlas. ¿Quién creyera que hasta el mes de Noviembre de 1804, se ha ignorado el número de Quinas que produce el suelo fecundo de Loja? No ignoro que los célebres Jussieu, de La-Condamine, el Barón de Humboldt y Bonpland han visitado esta Provincia en calidad de Botánicos. Pero sabemos que los trabajos del primero perecieron; el segundo sólo nombra tres especies, la roja, la blanca y la amarilla!, los últimos se detuvieron tan poco tiempo, que no les fue posible ver sino muy pocas.

Los extractos... aún está por elaborarse la primera onza! No hay quién ignore sus ventajas sobre la corteza en el uso médico, en el transporte y en el comercio. ¡Cuántas ocasiones, cuánto dinero perdido sin esperanza de resarcirles!

Ya debíamos saber el tiempo en que florece la Qui1a, si lo hace solamente una vez al año, o dos, como tengo fundamento para creerlo, en qué meses lo verifica, cuáudo bota la hoja, si lo hace sucesivamente como la mayor parte de las plantas equinocciales, qué tarda el fruto en perfeccionarse, y qué en germinar la semilla, si nace de estaca, cuál es el tiempo del empuje de la savia, si en esta estación es más activa la corteza, si la que nace en el término inferior es mejor que la del superior: si va degradando a proporción que se sube, o al contrario, el modo de podarle, la cualidad del terreno, si mejora su calidad con el cultivo, etc., etc. Hé aquí los bellos objetos que debían haber ocupado al Profesor de Lo- 
Rev. Acad. Colomb. Cienc. Ex. Fis. Nat. 42(Suplemento):30-39, octubre de 2018 doi: http://dx.doi.org/10.18257/raccefyn.734

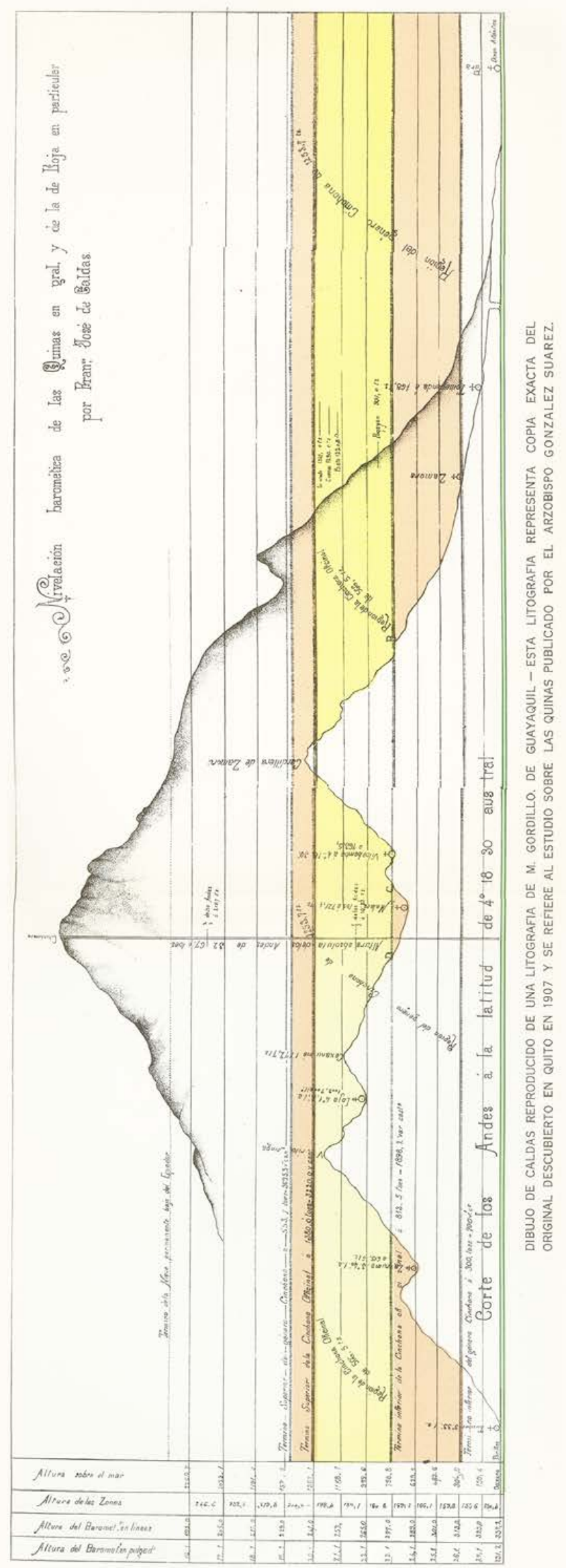


ja, hé aquí las cuestiones importantes cuya solución habrían mejorado el comercio y también la medicina.

\section{OTRAS ESPECIES DE OUINA}

Todas las especies del género Cinchona sin excepción nacen en la altura media de los Andes, vecinos al Ecuador. Los viajes, las herborizaciones de todos los botánicos que han trabajado en el Nuevo Mundo, prueban que no se hallan las Quinas sino desde $5^{\circ}$ de lat. austral, hasta $12^{\circ}$ de lat. boreal, en la dirección de Norte a Sur; y que del Este al Oeste sólo nacen sobre la Cordillera. Llamo al $1^{\circ}$ término boreal, al $2^{\circ}$ término austral, al $3^{\circ}$ término oriental, $\mathrm{y}$ al $4^{\circ}$ término occidental del género Cinchona. La distancia de los dos últimos es tan varia como la base de los Andes. No obstante no pasa de 40 leguas náuticas, ni baja de 25. Como la especie Officinal, tiene el género un término superior y otro inferior en que vegetan sus especies. Estos son demasiado interesantes: detengámonos un poco en ellos.

El Barón de Humboldt establece el término inferior de este género a 300 toesas, y el superior a 1.500 toesas sobre el mar. Suscribiendo gustoso al primero, creo que se debe levantar el segundo algunas toesas sobre esta determinación. En San Nicolás, al Oeste de Alausí, he observado la especie N. a 230,0 líneas del barómetro. Esta altura del mercurio da 1.553,7 toesas de elevación sobre el Pacífico. Aquí colocamos el término superior de las Cinchonas en nuestra nivelación. Es, pues, evidente, que la gran zona en que las encerró la Naturaleza tiene 1.253 toesas 7 (2.925,3 v. c.) de altura perpendicular.

Se opondrán contra estos límites las plantas febrífugas de las llanuras de Orinoco (1), Upatú y golfo de Santafé, Cumaná, las Quinas de Santo Domingo (2), de Jacquin y la de las islas de los Amigos Forster (3); y en fin las de Tacames (4). Pero

(1) El sabio Humboldt nos ha asegurado que las Quinas de la Angostura, Upatú, Golfo de Santafé y Cumaná, no pertenecen al género Cinchona. "La Quina de la Angostura, es la corteza de un nuevo género (cusparia febrifuga), germinibus quinquefolis ternatis alternis, crece cerca de Upatú en las Misiones de Caroni y en el Golfo de Santafé al Este de la nueva Barcelona. La Quina de Cumaná, muy febrifuga, viene del árbol cuspa, que tiene stipule, nulle, folia alterna. Estos dos árboles preciosos para la salud de los hombres vegetan a más de 200 leguas al Este de los Andes, o de la Patria de las Cinchonas... se ignora su analogía con la Quina de Tacames, que producen igualmente las Costas bajas del Mar del Sur, y que ningún naturalista ha observado". Geografia de las Plantas M. SS.

(2) E1 caballero Jacquin nos ha dicho que en la Isla de Santo Domingo crece un árbol que se llama Cinchona Caribea. Pero el juicioso Dn. Hipólito Ruiz (Quinología, pág. 9) hace ver qué distante está esta planta del género Cinchona, y que así este sabio Botánico, como el digno hijo de Linneo, se engañaron sobre el género de este vegetal.

(3) Con igual gradencia separa el mismo Ruiz del género Cinchona la C. Corymbifera de Forster. No hay más que leer con atención la página 12 de la Quinología de este Autor para quedar convencido que en Tongatabó no existe ninguna especie de Quina.

(4) La única especie que existe en las Costas del Océano Pacífico con el nombre de Cinchona es la de Tacames o Atacames. He visto ramos secos de este árbol remitidos de las bocas del río de Esmeraldas, a Quito, por Dn. Manuel José Pérez de Valencia. Creo que no pertenece al género Cinchona, aunque no he podido conseguir sus flores y frutos a pesar de los esfuerzos repetidos que he hecho. Tiene las hojas oblongas de 4-5 pulgadas de largo enterísimas, pecioladas, lampiñas, alternas y $\sin$ estipulas. Estos últimos caracteres jamás se han visto en ninguna de las Cinchonas conocidas. Todas poscen las hojas opuestas y estipuladas. Esperamos del celo del citado Dn. Manuel José Pérez de Valencia, otros esqueletos más perfectos, corteza y frutos de este árbol con que podremos fijar nuestras ideas sobre este punto. a ninguna de estas plantas las miran los verdaderos Botánicos como pertenecientes al género Cinchona. Basta reflexionar sobre las descripciones que de ellas nos han dado sus Autores; basta leer la Quinología de Ruiz, y la Geografía de las plantas de Humboldt para persuadirse que no hay Quinas fué. ra de los Andes equinocciales. En conclusión, queda este género confinado entre los límites que acabamos de prescribirles, $\mathrm{y}$ son, en resumen:

Término boreal...... $5^{\circ} 0^{\prime}$ lat. boreal

Término austral....... $12^{\circ} 0^{\prime}$ lat. austral

Suma......... $\overline{17^{\circ} 0^{\prime}}$ de Norte a Sur

Término oriental... 00,0

Término occidental. . 32,5 legs, distante del Ortal.

Término inferior.... 300,0 toesas sobre el mar

Término superior... 1.553,7 toesas sobre el mar

Diferencia... $\overline{1.253,7}$ toesas

Con estos preliminares podemos aproximarnos lo bastante en el cálculo de la extensión de superficie que produce las Cinchonas. Si multiplicamos la suma de los grados de latitud por la base media de los Andes, tendremos una Area 110,50 leguas cuadradas. Es preciso rebajar por lo menos $1 / 3$ por el espacioso terreno que ocupa la parte superior e inferior de la Cordillera en que jamás nacen las Quinas. Por consiguiente, de toda la extensión de la América Meridional, de las 600 mil leguas de superficie que presenta esta mitad del Nuevo Mundo sólo 7.367 producen las especies diferentes de este género (1). ¡Y cuánto hay que rebajar de este número: Aunque en todas se críe y pueda connaturalizarse, no en todas se hallan árboles de Quina; y aunque los Botánicos cuenten ya en este género muchas especies, son pocas las que se pueden poner al lado de la Cinchona Officinalis. Se deja sentir cuánta atención y cuánto deben economizarse estos bosques limitados y únicos sobre la tierra. Es preciso poner freno a los cortes indiscretos; es preciso dirigirles con preceptos; es preciso... digamos de una vez, el ramo de la Quina necesita ordenanzas sabias, con más razón que las minas de Méjico y del Perú.

Diez y siete especies de Quinas diferentes he colectado sólo en la Provincia de Quito, desde $1^{\circ} 30^{\prime}$ de latitud boreal, hasta $5^{\circ} 0$ ' de latitud austral. Todas las he diseñado, descripto y esqueletado cuidadosamente: de todas poseo porciones de corteza que llevo a la Capital del Virreinato como muestras. De estas 17 especies, 10 nacen en los bosques de Loja al lado de la Officinal con quien tántas veces se ha equivocado, y de que tánto se ha abusado con perjuicio del crédito del específico y de la salud del hombre.

Pero, ¿cuál es el grado de bondad de cada una de estas especies? ¿De qué virtudes se hallan dotadas, y qué estimación merecen de nuestra parte? En fin, ¿cuáles son los caracteres que las distinguen entre

\footnotetext{
(1) El cálculo es: $5^{\circ}+12^{\circ}=17^{\circ} \times 20$ leguas náuticas $=340$ $\times 32,5=11.050, \frac{11050}{3}=7.367$.
} 
sí? Hé aquí unas cuestiones importantes, cuestiones cuya solución está reservada a los profundos conocimiento del ikustre Mutis.

Cuando me haya restituído al lado de este $P a$ triarca de los Botánicos (1), cuando le haya presentado mis colecciones, cuando con esos ojos envejecidos en la distinción de más de veinte mil especies de plantas, examine, analice y aplique estas cortezas, entonces conocerá la Provincia de Quito, la Nueva Granada, y la Nación, cuánto debe a las luces de hombre tan grande. Se sabrá con firmeza cuál es la buena, la mediana, la inútil, qué lugares (2) les producen, a qué sitios se pueden transportar, con otros conocimientos útiles a la extracción, beneficio y comercio de este género importante.

Si es cierto que ya conocemos muchas especies, no lo es menos que aún nos falta mucho para podernos lisonjear de haber visto todas las Cinchonas que producen los Andes. Ah! Qué no debíamos esperar de Mutis, si poseyese esqueletos, cortezas, descripciones, etc., de cuantas especies nacen sobre esta cadena famosa de montañas. ;Cuántas relaciones! cuántos caracteres! cuántas luces necesarias para distinguirlas nos daría este Linneo del Nuevo Mundo: Apenas ha visto cinco que nacen en los países que

(1) Humboldt, este sabio viajero, cuyos talentos y luces no acabanos de admirar, es el autor de este elogio tan grande como conciso. Así se explica en su Geografia de las Plantas, obra sublime y filosófica que creyó digna de ser dedicada a Mutis.

(2) Mientras llega este tiempo, mientras damos la última mano a la Carta Quinológica del Reino, nos contentamos con indicar aquí los lugares en que se hallan árboles de Quina.

LUGARES DEL REINO EN QUE HAY ARBOLES DE QUINA

En la Gobernación de Popayán
Popayán
Pizofé: Hacienda
Poblazón: Pueblo
Chiribio: Hacienda
Chaupillacta y otros muchos
Almaguer
Guaytara
Guaytarilla
Ancuya
En el Corregimiento de Ibarra
Guaca: Pueblo
Intag: Pueblo
Quarabi: Anexo
Cunchi: Hacienda
En las cercanias de Quito
Nanegal
Perucho
Cansacoto
En el Correg. de Latacunga
Tagualó
Macuchi
Sigchos

ha recorrido, cuando nos da avisos importantes a nuestra salud, y abre un nuevo campo a trabajos gloriosos, e interesantes en la Física, en la Química y en la Medicina. Si deseamos una sólida reforma sobre las Quinas, si queremos organizar este Ramo, y darle, como es justo, el último grado de perfección de que es capaz, es preciso comenzar por un examen detenido de los Andes equinocciales desde $5^{\circ}$ de la. titud boreal, hasta los $12^{\circ}$ de latitud austral. ; Cuántas especies hasta hoy desconocidas! Cuántas que tal vez igualen o excedan en virtud a la de Loja y Calisaya! I'ero yo salgo de los límites que me prescribe mi condición privada. Este punto pertenece al Jefe ilustrado que hoy manda esta Colonia.

\section{CONCLUSION}

De todo lo dicho hasta aquí resulta: que en toda la América Meridional, sólo en las 200 leguas de las inmediaciones de Loja se halla la verdadera Cinchonu Officinalis, la única que se remite por cuenta de S. M. a la Botica Real; que acotándola bajo los límites que prescribe la Carta adjunta, corrigiendo algunos abusos, y sobre todo, promoviendo los plantíos, pueden proveer para siempre esos bosques, no sólo de las 4 - 500 arrobas que se extraen hoy sino de una cantidad mucho mayor; que animando los trasplantes a los otros lugares análogos del Reino, se multiplicará este específico prodigiosamente con notables ventajas de los Pueblos y del Rey; que sujetando al Profesor de Loja a las luces y dirección del célebre Mutis, saldrá del letargo en que hace trece años se halla sepultado; se perfeccionarán, o por mejor decir, se echarán los fundamentos a una Administración abandonada hasta hoy al capricho y a la igmorancia de los Corregidores de esa Ciudad; que las otras especies de Quinas inferiores en virtud. pueden sin perjuicio de S. M. dejarse en manos de los vasallos; que esta providencia digna de un Soberano clemente sacará a muchas familias de la miseria y reanimará considerablemente el comercio moribundo de la Provincia de Quito. En fin, que para impedir los cortes indiscretos, y los abusos de los particulares, se formen ordenanzas que prescriban el método, la cantidad, el tiempo en que deben verificarse los acopios.

Quito y Marzo 16 de 1805.

Es copia de su original que queda en esta Secretaría de la Presidencia de mi cargo, de que certifico.

Quito, 21 de Mayo de 1805.

JUAN DE DIOS MORALES 